\title{
PENILAIAN KINERJA BERBASIS RELIABILITY PADA CONTINUOUS CASTING MACHINE 3 (CCM 3) PT KRAKATAU STEEL (Persero) Tbk MENGGUNAKAN METODE RELIABILITY AVAILABILITY MAINTAINABILITY DAN COST OF UNRELIABILITY
}

\author{
${ }^{1}$ Ika Praesita, ${ }^{2}$ Judi Alhilman, ${ }^{3}$ Nopendri \\ 1,2,3Program Studi Teknik Industri, Fakultas Rekayasa Industri, Telkom University \\ 1ika.praesita@gmail.com, ${ }^{2}$ judi.alhilman@gmail.com, ${ }^{3}$ nopendri@telkomuniversity.ac.id
}

\begin{abstract}
Abstrak-Industri baja merupakan industri strategis yang digunakan sebagai bahan baku penting bagi industri-industri secara keseluruhan, baik untuk infrastruktur, produksi barang modal, alat transportasi, otomotif, hingga persenjataan. World Steel Association mencatat, konsumsi baja per kapita pada tahun 2014, Indonesia mencapai 62,2 $\mathrm{kg} / \mathrm{kapita}$, namun angka tersebut masih tergolong rendah. Pemerintah Indonesia saat ini sadar akan hal tersebut dan merencanakan akan meningkatkan konsumsi baja nasional. Salah satu cara dalam mengurangi kerugian yang terjadi adalah dengan meningkatkan RAM (Reliability Availability Maintainability) dari mesin CCM 3. Dalam perhitungan RAM digunakan pemodelan RBD (Reliability Block Diagram) untuk mempermudah pemahaman terhadap sistem. Biaya yang dihasilkan dari masalah RAM dapat diketahui dengan menggunakan metode COUR (Cost of Unreliability). Hasil pengolahan data menggunakan RAM dengan pemodelan RBD didapatkan nilai reliability system sebesar $28,44 \%$ pada $\mathrm{t}=936$ dan nilai maintainability mesin sebesar $100 \%$ minimal membutuhkan waktu 13 jam. Dengan nilai inherent availability sebesar 99,47\% dan operational availability sebesar $99,44 \%$. Berdasarkan evaluasi yang telah dilakukan dengan menggunakan kebijakan perusahaan dan Key Performance Indicator IVARA, indikator availability telah mencapai target indikator yang diberikan. Dari hasil perhitungan menggunakan RAM didapatkan nilai COUR sebesar Rp 5.031.295.257,00 berdasarkan pada downtime atau corrective time.
\end{abstract}

Kata kunci: Reliability, Availability, Maintainability, Cost of Unreliability, Key Performance Indicator, Reliability Block Diagram

\section{PENDAHULUAN}

PT Krakatau Steel (Persero) Tbk merupakan perusahaan penghasil baja terpadu dan terbesar di Indonesia. Kapasitas produksi baja yang dimiliki PT Krakatau Steel (Persero) Tbk mencapai 3,15 juta ton[1]. Sebagai salah satu perusahaan besi baja terbesar di Indonesia, PT Krakatau Steel (Persero) Tbk mendapatkan banyak permintaan baik dari dalam maupun luar negeri. Oleh karena itu, perusahaan harus selalu berusaha keras untuk menjaga kredibilitas perusahaannya agar tidak terdapat komplain dari konsumen. Hal ini dilakukan di semua pabrik yang ada di PT Krakatau Steel (Persero) Tbk salah satu pabriknya yaitu SSP (Slab Steel Plant). Namun, saat ini SSP sedang tidak beroperasi dikarenakan mahalnya bahan baku yang hampir sama dengan biaya import baja slab. Kondisi tersebut tidak membuat aktivitas di SSP menjadi berhenti, seperti kegiatan preventive maintenance yang dilakukan agar mesin selalu berada pada kondisi baik. Mesin-mesin yang digunakan pada proses produksi dalam SSP ini hampir semua sudah pernah dilakukan revitalization atau upgrade. Berdasarkan hasil wawancara dengan salah satu pekerja di SSP, terdapat satu mesin yang belum pernah dilakukan revitalization atau upgrade yaitu mesin CCM 3 (Continuous Casting Machine 3).

Angka downtime yang terjadi pada mesin CCM 3 meningkat setiap tahunnya dan mencapai angka tertinggi pada tahun 2013 sebesar 189,47 jam, yang berarti sebagian besar proses produksi di mesin CCM 3 tidak berjalan sesuai rencana dan tentunya menimbulkan kerugian bagi perusahaan. Angka downtime yang terjadi diakibatkan oleh subsistem yang tidak bekerja dengan seharusnya. Hal ini dikarenakan belum adanya maintenance yang efektif untuk menanggulangi masalah tersebut. Apabila terjadi gangguan pada mesin CCM 3 seluruh proses harus berhenti, hal tersebut menyebabkan kerugian terutama dalam hal revenue yang akan didapat oleh perusahaan[2]. Maka dari itu, perlu adanya perhatian khusus pada mesin CCM 3 untuk mengetahui performansi kerja dilihat dari RAM (Reliability Availability Maintainability) dan COUR (Cost of Unreliability) untuk mengetahui seberapa besar biaya yang dikeluarkan akibat masalah RAM.

\section{STUDI LITERATUR}

\section{A. RAM}

RAM merupakan sebuah metode yang digunakan untuk memprediksi kinerja reliability, availability dan maintainability suatu sistem dan sebagai alat untuk 
memberikan dasar untuk optimasi dari sistem. Umumnya pada sistem yang kompleks, sistem tersebut dibagi menjadi beberapa subsistem, sehingga dapat diperiksa lebih detail dan dapat diberikan perubahan-perubahan lebih rinci untuk mengoptimalkan kinerja dari keseluruhan sistem. Selain itu, RAM dapat digunakan untuk mengidentifikasi subsistem yang kritis dan sensitif dalam sistem produksi, yang dapat memberikan efek besar pada kinerja sistem.

Metode RAM membutuhkan pemahaman mendalam akan cara sisem bekerja, untuk mengetahui secara detail bagian yang akan menyebabkan kerusakan, ataupun bagian yang harus diperbaiki. Maka dari itu diperlukan sebuah model yang dapat merepresentasikan bagaimana sistem yang sedang diteliti bekerja. Pemodelan RBD (Reliability Block Diagram) dapat digunakan untuk memodelkan sistem yang sedang diteliti[3].

\section{Reliability}

Reliabilty merupakan probabilitas suatu sistem dapat berjalan tanpa adanya kegagalan dalam periode waktu tertentu saat kondisi sistem sedang beroperasi[4]. Nilai reliability suatu komponen maupun sistem biasanya dinyatakan dalam bentuk probabilitas atau peluang, dengan nilai $\mathrm{R}$ (Reliability) antara 0 - 1. Keandalan dari sebuah komponen dapat menurun sesuai dengan bertambahnya waktu[5].

a. Distribusi eksponensial

$$
R(T)=e^{-\lambda T}
$$

b. Distribusi normal

$$
R(T)=\int_{T}^{\infty} \frac{1}{\sigma_{T} \sqrt{2 \pi}} e^{-\frac{1}{2}}\left(\frac{T-\bar{T}}{\sigma_{T}}\right)
$$

c. Distribusi weibull

$$
R(T)=e^{-\left(\frac{T-\gamma}{\eta}\right)^{\beta}}
$$

\section{Availability}

Availability adalah Reliabilty merupakan probabilitas suatu sistem dapat berjalan tanpa adanya kegagalan dalam periode waktu tertentu saat kondisi sistem sedang beroperasi [6]. Availability merupakan fungsi dari suatu siklus waktu operasi dan waktu downtime dan merupakan ukuran keberhasilan suatu sistem untuk melaksanakan misi operasi tertentu saat waktu pemanggilan sistem tidak ditentukan.

a. Inherent availability

$$
A_{I}=\frac{\text { MTBF }}{\text { MTBF+MTTR }}
$$

b. Operational availability

$$
A_{o}=\frac{\text { uptime }}{\text { siklus operasi }}
$$

Indikator dalam pengukuran kinerja dibagi menjadi dua bagian, yaitu Leading Indicator dan Lagging Indicator. Leading Indicator sebagai indikator kinerja availability yang telah direncanakan sebelumnya (scheduled maintenance) dan lagging Indicator sebagai cara perhitungan nilai availability sistem eksisting dari data kerusakan masa lalu[7].

\section{Maintainability}

Maintainability merupakan probabilitas suatu sistem atau komponen yang rusak dikembalikan kefungsi awal dalam periode waktu yang telah disepakati dan dilakukan dengan prosedur perawatan tertentu[8].

$$
M(t)=1-\exp \left(-\frac{t}{M T T R}\right)
$$

\section{B. COUR}

COUR merupakan seluruh biaya yang dihasilkan dari seluruh situasi yang berhubungan dengan masalah kegagalan, termasuk biaya yang berhubungan dengan program perawatan yang buruk[9]. Untuk mendapatkan COUR, maka sebaiknya memulai dengan gambaran besar dan membantu program peningkatan biaya langsung, yaitu dengan mengidentifikasi sumber masalah biaya, level masalah dan masalah apa saja yang muncul. COUR mempelajari fasilitas produksi sebagai suatu jaringan untuk sistem keandalan, dan biaya yang terjadi saat sistem gagal untuk melakukan pekerjaannya [10].

\section{METODOLOGI PENELITIAN}

Konsep dalam penelitian ini diawali dengan melakukan penentuan distribusi pada data kerusakan yang di dalamnya terdapat time to repair, downtime dan time between failure Penentuan distribusi dilakukan dengan menggunFrbdakan software Minitab 17. Setelah didapatkan distribusi yang paling baik, dapat dilakukan plotting data untuk menentukan parameter distribusi terpilih, yang dilakukan dengan menggunakan software AvSim+ 9.0. Hasil yang didapatkan dari uji tersebut adalah nilai MTBF, MDT, dan MTTR yang akan digunakan dalam perhitungan RAM dan COUR.

Perhitungan nilai dari reliability, availability, maintainability secara analytical dapat dilakukan dengan menggunakan nilai parameter distribusi dari setiap subsistem dan pemodelan RBD yang digunakan dalam memodelkan subsistem sistem CCM 3 agar mempermudah perhitungan dari RAM sistem. MTBF dari unit digunakan untuk menentukan reliability mesin, dan MTTR digunakan untuk menentukan maintainability mesin. Nilai availability dilakukan dengan menggunakan dua perhitungan, yaitu inherent availability dan operational availability. Data yang telah didapat sebelumnya dapat dibandingkan dengan menggunakan nilai availability kebijakan perusahaan dan key performance indicator IVARA.

Kerugian yang ditimbukan dari masalah RAM dapat dilihat dari sudut pandang bisnis, untuk mengetahui dengan pasti nilai dari seluruh peluang. Nilai tersebut didapatkan dari biaya-biaya yang dihasilkan dari situasi-situasi kegagalan yang muncul. Untuk mengetahui seberapa besar sebenarnya seluruh biaya yang dihasilkan, yaitu dengan menggunakan metode COUR. Dengan menggunakan COUR, selain sebagai untuk melihat besarnya biaya yang dikeluarkan karena masalah RAM, tetapi juga menjadi parameter untuk melihat perubahan yang ditimbulkan oleh usulan peningkatan RAM. 


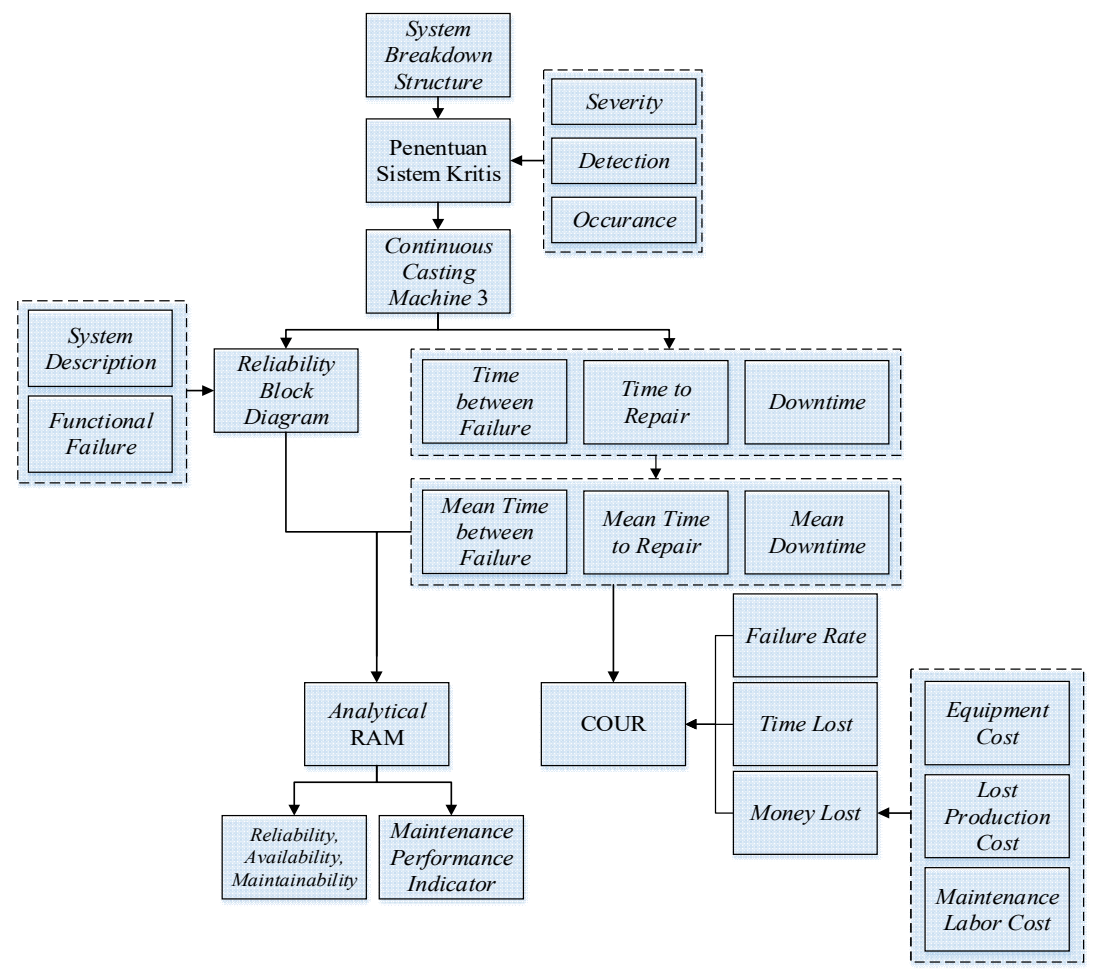

Gambar 1 Metodologi penelitian

Perhitungan COUR dibagi menjadi tiga, yaitu failure rate, time lost, dan money lost. Data yang dibutuhkan dalam perhitungan COUR adalah equipment cost, lost production cost, dan maintenance labor cost. Keseluruhan konsep yang digunakan dalam penelitian ini dapat dilihat pada Gambar 1.

\section{HASIL DAN ANALISIS}

A. Penentuan distribusi terpilih dan plotting distribusi

Data kerusakan yang digunakan pada penelitian ini adalah data kerusakan Januari 2011 - Desember 2013. Penentuan distribusi pada data Time to Failure, Downtime, dan Time to Repair dilakukan dengan menggunakan uji Anderson-Darling (AD).

TABEL I

DISTRIBUSI TERPILIH DAN PARAMETER TIME TO FAILURE

\begin{tabular}{|c|c|c|c|}
\hline \multirow{2}{*}{ Subsistem } & \multirow{2}{*}{ Distribusi Terpilih } & \multicolumn{2}{|c|}{ Parameter } \\
\cline { 3 - 4 } & & $\boldsymbol{\eta}$ & $\boldsymbol{\beta}$ \\
\hline Ladle Turret & Weibull & 2366,32 & 4,43715 \\
\hline Tundish Car & Weibull & 4278,78 & 9,79755 \\
\hline Mould & Weibull & 996,902 & 5,30505 \\
\hline Segment & Weibull & 1179,7 & 7,00783 \\
\hline TCM & Weibull & 1089,82 & 7,33381 \\
\hline
\end{tabular}

Semakin kecil nilai AD maka distribusi tersebut semakin mewakili distribusi terhadap penyebaran data tersebut. Nilai PValue digunakan untuk mengetahui suatu hipotesis ditolak atau diterima dengan ketentuan $\mathrm{H}_{0}$ ditolak jika P-Value $<\alpha$. Setelah penentuan distribusi, maka dilakukan plotting distribusi untuk menentukan nilai parameter. Tabel I dan Tabel II menunjukkan distribusi terpilih dan nilai parameter dari setiap subsistem.

TABEL II

DISTRIBUSI TERPILIH DAN PARAMETER DOWNTIME

\begin{tabular}{|c|c|c|c|}
\hline \multirow{2}{*}{ Subsistem } & \multirow{2}{*}{ Distribusi Terpilih } & \multicolumn{2}{|c|}{ Parameter } \\
\cline { 3 - 4 } & & $\boldsymbol{\eta}$ & $\boldsymbol{\beta}$ \\
\hline Ladle Turret & Weibull & 1,47078 & 3,03943 \\
\hline Tundish Car & Weibull & 1,96212 & 2,39291 \\
\hline Mould & Weibull & 1,67772 & 3,47518 \\
\hline Segment & Weibull & 1,6866 & 2,98575 \\
\hline TCM & Weibull & 1,40197 & 3,18123 \\
\hline
\end{tabular}

TABEL III

DISTRIBUSI TERPILIH DAN PARAMETER TIME TO REPAIR

\begin{tabular}{|c|c|c|c|}
\hline \multirow{2}{*}{ Subsistem } & \multirow{2}{*}{ Distribusi Terpilih } & \multicolumn{2}{|c|}{ Parameter } \\
\cline { 3 - 4 } & & $\boldsymbol{\eta}$ & $\boldsymbol{\beta}$ \\
\hline Ladle Turret & Weibull & 1,47078 & 3,03943 \\
\hline Tundish Car & Weibull & 1,96212 & 2,39291 \\
\hline Mould & Weibull & 1,67772 & 3,47518 \\
\hline Segment & Weibull & 1,6866 & 2,98575 \\
\hline TCM & Weibull & 1,40197 & 3,18123 \\
\hline
\end{tabular}


B. Perhitungan reliability

Perhitungan reliability yang dilakukan pada sistem CCM 3 menggunakan data permodelan RBD agar dapat melihat hubungan antar subsistem. Pemodelan RBD dari mesin CCM 3 dapat dilihat pada Gambar 2.

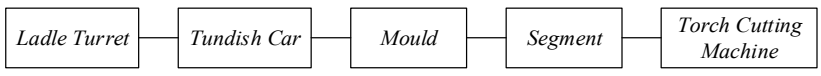

Gambar 2 RBD sistem CCM 3

Waktu yang digunakan pada perhitungan reliability antara 24 - 936 jam dengan interval 24 jam dan didapatkan hasil reliability system pada $\mathrm{t}=936$ jam sebesar 28,44\%. Hasil perhitungan reliability dapat dilihat pada Tabel IV dan hasil dari reliability system dapat dilihat pada Tabel V.

TABEL IV

PERHITUNGAN RELIABILITY

\begin{tabular}{|c|c|c|c|c|c|c|}
\hline t & $\begin{array}{c}\text { Ladle } \\
\text { Turret }\end{array}$ & $\begin{array}{c}\text { Tundish } \\
\text { Car }\end{array}$ & Mould & Segment & TCM & $\begin{array}{c}\text { Reliability } \\
\text { System }\end{array}$ \\
\hline 24 & $100 \%$ & $100 \%$ & $100 \%$ & $100 \%$ & $100 \%$ & $100 \%$ \\
\hline 48 & $100 \%$ & $100 \%$ & $100 \%$ & $100 \%$ & $100 \%$ & $100 \%$ \\
\hline 72 & $100 \%$ & $100 \%$ & $100 \%$ & $100 \%$ & $100 \%$ & $100 \%$ \\
\hline 96 & $100 \%$ & $100 \%$ & $100 \%$ & $100 \%$ & $100 \%$ & $100 \%$ \\
\hline 120 & $100 \%$ & $100 \%$ & $100 \%$ & $100 \%$ & $100 \%$ & $100 \%$ \\
\hline 144 & $100 \%$ & $100 \%$ & $100 \%$ & $100 \%$ & $100 \%$ & $100 \%$ \\
\hline 168 & $100 \%$ & $100 \%$ & $99,99 \%$ & $100 \%$ & $100 \%$ & $99,99 \%$ \\
\hline
\end{tabular}

TABEL V

RELIABILITY SYSTEM

\begin{tabular}{|c|c|c|c|c|c|}
\hline $\mathbf{t}$ & $\begin{array}{c}\text { Reliability } \\
\text { System }\end{array}$ & $\mathbf{t}$ & $\begin{array}{c}\text { Reliability } \\
\text { System }\end{array}$ & $\mathbf{t}$ & $\begin{array}{c}\text { Reliability } \\
\text { System }\end{array}$ \\
\hline 24 & $100 \%$ & 336 & $99,64 \%$ & 648 & $86,76 \%$ \\
\hline 48 & $100 \%$ & 360 & $99,47 \%$ & 672 & $83,91 \%$ \\
\hline 72 & $100 \%$ & 384 & $99,25 \%$ & 696 & $80,64 \%$ \\
\hline 96 & $100 \%$ & 408 & $98,96 \%$ & 720 & $76,93 \%$ \\
\hline 120 & $100 \%$ & 432 & $98,57 \%$ & 744 & $72,76 \%$ \\
\hline 144 & $100 \%$ & 456 & $98,08 \%$ & 768 & $68,14 \%$ \\
\hline 168 & $99,99 \%$ & 480 & $97,45 \%$ & 792 & $63,11 \%$ \\
\hline 192 & $99,98 \%$ & 504 & $96,66 \%$ & 816 & $57,70 \%$ \\
\hline 216 & $99,97 \%$ & 528 & $95,68 \%$ & 840 & $52,00 \%$ \\
\hline 240 & $99,94 \%$ & 552 & $94,49 \%$ & 864 & $46,09 \%$ \\
\hline 264 & $99,90 \%$ & 576 & $93,03 \%$ & 888 & $40,11 \%$ \\
\hline 288 & $99,84 \%$ & 600 & $91,28 \%$ & 912 & $34,18 \%$ \\
\hline 312 & $99,76 \%$ & 624 & $89,20 \%$ & 936 & $28,44 \%$ \\
\hline
\end{tabular}

\section{Perhitungan maintainability}

Perhitungan maintainability dilakukan dengan menggunakan data Time to Repair dan didapatkan maintainability dari setiap subsistem pada sistem CCM 3. Waktu yang digunakan pada perhitungan maintainability antara 1 - 13 jam dengan interval satu jam. Hasil perhitungan maintainability sistem CCM 3 dapat dilihat pada Tabel VI dan Tabel VII.
TABEL VI

PERHITUNGAN MAINTAINABILITY

\begin{tabular}{|c|c|c|c|c|c|}
\hline $\mathbf{t}$ & $\begin{array}{c}\text { Ladle } \\
\text { Turret }\end{array}$ & $\begin{array}{c}\text { Tundish } \\
\text { Car }\end{array}$ & Mould & $\begin{array}{c}\text { Segmen } \\
\boldsymbol{t}\end{array}$ & TCM \\
\hline 1 & $53,28 \%$ & $43,73 \%$ & $\begin{array}{c}48,45 \\
\%\end{array}$ & $48,53 \%$ & $\begin{array}{c}54,91 \\
\%\end{array}$ \\
\hline 2 & $78,17 \%$ & $68,33 \%$ & $\begin{array}{c}73,43 \\
\%\end{array}$ & $73,50 \%$ & $\begin{array}{c}79,67 \\
\%\end{array}$ \\
\hline 3 & $89,80 \%$ & $82,18 \%$ & $\begin{array}{c}86,30 \\
\%\end{array}$ & $86,36 \%$ & $\begin{array}{c}90,84 \\
\%\end{array}$ \\
\hline 4 & $95,23 \%$ & $89,97 \%$ & $\begin{array}{c}92,94 \\
\%\end{array}$ & $92,98 \%$ & $\begin{array}{c}95,87 \\
\%\end{array}$ \\
\hline 5 & $97,77 \%$ & $94,36 \%$ & $\begin{array}{c}96,36 \\
\%\end{array}$ & $96,39 \%$ & $\begin{array}{c}98,14 \\
\%\end{array}$ \\
\hline 6 & $98,96 \%$ & $96,82 \%$ & $\begin{array}{c}98,12 \\
\%\end{array}$ & $98,14 \%$ & $\begin{array}{c}99,16 \\
\%\end{array}$ \\
\hline 7 & $99,51 \%$ & $98,21 \%$ & $\begin{array}{c}99,03 \\
\%\end{array}$ & $99,04 \%$ & $\begin{array}{c}99,62 \\
\%\end{array}$ \\
\hline 8 & $99,77 \%$ & $98,99 \%$ & $\begin{array}{c}99,50 \\
\%\end{array}$ & $99,51 \%$ & $\begin{array}{c}99,83 \\
\%\end{array}$ \\
\hline 9 & $99,89 \%$ & $99,43 \%$ & $\begin{array}{c}99,74 \\
\%\end{array}$ & $99,75 \%$ & $\begin{array}{c}99,92 \\
\%\end{array}$ \\
\hline 10 & $99,95 \%$ & $99,68 \%$ & $\begin{array}{c}99,87 \\
\%\end{array}$ & $99,87 \%$ & $\begin{array}{c}99,97 \\
\%\end{array}$ \\
\hline 11 & $99,98 \%$ & $99,82 \%$ & $\begin{array}{c}99,93 \\
\%\end{array}$ & $99,93 \%$ & $\begin{array}{c}99,98 \\
\%\end{array}$ \\
\hline 12 & $99,99 \%$ & $99,90 \%$ & $\begin{array}{c}99,96 \\
\%\end{array}$ & $99,97 \%$ & $\begin{array}{c}99,99 \\
\%\end{array}$ \\
\hline 13 & $99,99 \%$ & $99,94 \%$ & $\begin{array}{c}99,98 \\
\%\end{array}$ & $99,98 \%$ & $\begin{array}{c}100 \% \\
\%\end{array}$ \\
\hline
\end{tabular}

D. Perhitungan availability

Perhitungan availability yang dilakukan pada sistem CCM 3 menggunakan data pemodelan RBD agar dapat melihat hubungan antar subsistem. Perhitungan availability dibagi menjadi dua, yaitu inherent availability dan operational availability.

1. Perhitungan inherent availability

Perhitungan inherent availability menggunakan data Time to Repair dan Time to Failure dengan menggunakan pemodelan RBD. Perhitungan inherent availability dari setiap subsistem pada sistem CCM 3 dapat dilihat pada Tabel VIII.

TABEL VII

INHERENT AVAILABILITY

\begin{tabular}{|c|c|c|c|c|c|}
\hline $\begin{array}{c}\text { Ladle } \\
\text { Turret }\end{array}$ & $\begin{array}{c}\text { Tundish } \\
\text { Car }\end{array}$ & Mould & $\begin{array}{c}\text { Segmen } \\
\boldsymbol{t}\end{array}$ & TCM & $\begin{array}{c}\text { Availability } \\
\text { System }\end{array}$ \\
\hline $99,94 \%$ & $99,96 \%$ & $99,84 \%$ & $99,86 \%$ & $99,88 \%$ & $99,47 \%$ \\
\hline
\end{tabular}

\section{Perhitungan operational availability}

Perhitungan operational availability menggunakan data operational time dan downtime dengan menggunakan pemodelan RBD. Perhitungan operational availability dari setiap subsistem pada sistem CCM 3 dapat dilihat pada Tabel IX.

TABEL VIII

OPERATIONAL AVAILABILITY

\begin{tabular}{|c|c|c|c|c|c|}
\hline $\begin{array}{c}\text { Ladle } \\
\text { Turret }\end{array}$ & $\begin{array}{c}\text { Tundish } \\
\text { Car }\end{array}$ & Mould & Segment & TCM & $\begin{array}{c}\text { Availability } \\
\text { System }\end{array}$ \\
\hline $99,93 \%$ & $99,95 \%$ & $\begin{array}{c}99,83 \\
\%\end{array}$ & $99,86 \%$ & $99,87 \%$ & $99,44 \%$ \\
\hline
\end{tabular}


Berdasarkan target perusahaan nilai availability minimal sebesar $85 \%$ dan target berdasarkan key performance indicator IVARA minimal sebesar 95\%, dapat dikatakan bahwa inherent availability sebagai leading indicator dan operational availability sebagai lagging indicator sudah mencapai target perusahaan dan key performance indicator IVARA. Hal ini dapat ditunjukkan dengan nilai dari semua subsistem yang mencapai target.

\section{E. Perhitungan COUR}

Perhitungan COUR dilakukan dalam tiga tahap perhitungan, yaitu failure rate, time lost, dan money lost [11].

1. Perhitungan failure rate

Tahap pertama dalam perhitungan COUR adalah menentukan nilai failure rate dari masing-masing subsistem pada sistem CCM 3. Berdasarkan perhitungan failure rate yang dapat disimpulkan bahwa semakin besar number of failure, maka akan semakin besar juga nilai failure rate, begitu pula sebaliknya.

TABEL IX

PERHITUNGAN FAILURE RATE

\begin{tabular}{|c|c|c|c|c|c|}
\hline & $\begin{array}{c}\text { Ladle } \\
\text { Turret }\end{array}$ & $\begin{array}{c}\text { Tundish } \\
\text { Car }\end{array}$ & Mould & Segment & TCM \\
\hline $\begin{array}{c}\text { Study } \\
\text { Interval }\end{array}$ & 25200 & 25200 & 25200 & 25200 & 25200 \\
\hline $\begin{array}{c}\text { Number } \\
\text { of } \\
\text { Failures }\end{array}$ & 13 & 7 & 29 & 24 & 26 \\
\hline $\begin{array}{c}\text { MTBF } \\
\text { jam) }\end{array}$ & 2157,68 & 4067,07 & 918,45 & 1103,60 & 1021,90 \\
\hline $\begin{array}{c}\text { Failure } \\
\text { Rate }\end{array}$ & $0,046 \%$ & $0,0246 \%$ & $0,1089 \%$ & $0,0906 \%$ & $\begin{array}{c}0,0979 \\
\%\end{array}$ \\
\hline
\end{tabular}

2. Perhitungan time lost

Tahap kedua dalam perhitungan COUR adalah mencari nilai time lost dari seluruh kegagalan yang terjadi selama observasi dilakukan. Time lost digunakan untuk mengidentifikasi masalah yang terjadi yang menyebabkan hilangnya waktu operasional produksi. Time lost dihitung dari dua data waktu yaitu berdasarkan time lost corrective time dan time lost downtime. Namun, pada penelitian ini data waktu yang dimiliki adalah downtime dan data time to repair yang diasumsikan sama dengan downtime.

TABEL X

PERHITUNGAN CORRECTIVE TIME LOST

\begin{tabular}{|c|c|c|c|c|c|}
\hline & $\begin{array}{c}\text { Ladle } \\
\text { Turret }\end{array}$ & $\begin{array}{c}\text { Tundish } \\
\text { Slide }\end{array}$ & Mould & $\begin{array}{c}\text { Segmen } \\
\boldsymbol{t}\end{array}$ & TCM \\
\hline Failure Rate & $0,05 \%$ & $0,02 \%$ & $0,11 \%$ & $0,09 \%$ & $\begin{array}{c}0,10 \\
\%\end{array}$ \\
\hline $\begin{array}{c}\text { Number of } \\
\text { Failures }\end{array}$ & 13 & 7 & 29 & 24 & 26 \\
\hline $\begin{array}{c}\text { Corrective } \\
\text { Time/Failure } \\
\text { (MTTR) }\end{array}$ & 1,31 & 1,74 & 1,51 & 1,51 & 1,26 \\
\hline $\begin{array}{c}\text { Corrective } \\
\text { Lost Time } \\
\text { Hours/3 } \\
\text { years }\end{array}$ & 17,08 & 12,18 & 43,76 & 36,14 & 32,64 \\
\hline
\end{tabular}

TABEL XI

PERHITUNGAN DOWNTIME LOST TIME

\begin{tabular}{|c|c|c|c|c|c|}
\hline & $\begin{array}{c}\text { Ladle } \\
\text { Turret }\end{array}$ & $\begin{array}{c}\text { Tundish } \\
\text { Slide }\end{array}$ & Mould & $\begin{array}{c}\text { Segmen } \\
\boldsymbol{t}\end{array}$ & TCM \\
\hline Failure Rate & $0,05 \%$ & $0,02 \%$ & $0,11 \%$ & $0,09 \%$ & $\begin{array}{c}0,10 \\
\%\end{array}$ \\
\hline $\begin{array}{c}\text { Number of } \\
\text { Failures }\end{array}$ & 13 & 7 & 29 & 24 & 26 \\
\hline DT/Failure & 1,31 & 1,74 & 1,51 & 1,51 & 1,26 \\
\hline $\begin{array}{c}\text { DT Hours/3 } \\
\text { years }\end{array}$ & 17,08 & 12,18 & 43,76 & 36,14 & 32,64 \\
\hline
\end{tabular}

3. Perhitungan money lost

Tahap ketiga dalam perhitungan COUR adalah mencari nilai money lost. Perhitungan money lost digunakan untuk membantu mengidentifikasi masalah biaya.

TABEL XII

MONEY LOST BERDASARKAN CORRECTIVE TIME

\begin{tabular}{|c|c|c|c|}
\hline & Ladle Turret & Tundish Car & Mould \\
\hline $\begin{array}{c}\text { Corrective } \\
\text { Lost Time } \\
\text { (Hrs/3 } \\
\text { Years) }\end{array}$ & 17,08381966 & 12,17503142 & 43,75972693 \\
\hline $\begin{array}{c}\text { Lost } \\
\text { Production } \\
\text { Cost }\end{array}$ & $\begin{array}{l}\mathrm{Rp} \\
597.933 .688\end{array}$ & $\mathrm{Rp}$ & $\mathrm{R}$ \\
\hline $\begin{array}{c}\text { Equipment/ } \\
\text { Sparepart } \\
\text { Cost }\end{array}$ & $\mathrm{Rp} 2.318 .842$ & $\mathrm{Rp} 2.225 .897$ & $\mathrm{Rp}$ \\
\hline $\begin{array}{c}\text { Labor } \\
\text { Maintenanc } \\
\text { e Cost }\end{array}$ & $\mathrm{Rp} 1.245 .752$ & $\mathrm{Rp} 887.80969 .767$, & $\mathrm{Rp} 3.190 .959$ \\
\hline $\begin{array}{c}\text { Corrective } \\
\text { COUR }\end{array}$ & 601.498 .283 & 429.239 .800 & 1.540 .278 .169 \\
\hline \multicolumn{2}{|c|}{$\mathrm{Rp}$} & $\mathrm{Rp}$ \\
\hline
\end{tabular}

TABEL XIII

MONEY LOST BERDASARKAN CORRECTIVE TIME (LANJUTAN)

\begin{tabular}{|c|c|c|}
\hline $\begin{array}{c}\text { Corrective Lost Time } \\
\text { (Hrs/3 Years) }\end{array}$ & 36,13884014 & TCM \\
\hline Lost Production Cost & $\mathrm{Rp} 1.264 .859 .405$ & $\mathrm{Rp} 1.142 .343 .844$ \\
\hline $\begin{array}{c}\text { Equipment/Sparepart } \\
\text { Cost }\end{array}$ & $\mathrm{Rp} \mathrm{4.649.861}$ & $\mathrm{Rp} 3.669 .408$ \\
\hline Labor Maintenance Cost & $\mathrm{Rp} 2.635 .244$ & $\mathrm{Rp} 2.379 .991$ \\
\hline Corrective COUR & $\mathrm{Rp} 1.272 .144 .510$ & $\mathrm{Rp} 1.148 .393 .244$ \\
\hline
\end{tabular}

TABEL XIV

MONEY LOST BERDASARKAN DOWNTIME

\begin{tabular}{|c|c|c|c|}
\hline & Ladle Turret & Tundish Car & Mould \\
\hline $\begin{array}{c}\text { Downtime Lost } \\
\text { Time (Hrs/3 } \\
\text { Years) }\end{array}$ & 17,08381966 & 12,17503142 & 43,75972693 \\
\hline $\begin{array}{c}\text { Lost } \\
\text { Production } \\
\text { Cost }\end{array}$ & $\mathrm{Rp}$ & $\mathrm{Rp}$ & $\mathrm{Rp}$ \\
\hline $\begin{array}{c}\text { Equipment/ } \\
\text { Sparepart Cost }\end{array}$ & $\mathrm{Rp} 2.318 .842$ & $\mathrm{Rp} 2.225 .897$ & $\mathrm{Rp} \mathrm{5.496.767,}$ \\
\hline $\begin{array}{c}\text { Labor } \\
\text { Maintenance } \\
\text { Cost }\end{array}$ & $\mathrm{Rp} 1.245 .752$ & $\mathrm{Rp} 887.803$ & $\mathrm{Rp} \mathrm{3.190.959}$ \\
\hline $\begin{array}{c}\text { Downtime } \\
\text { COUR }\end{array}$ & $\begin{array}{c}\mathrm{Rp} \\
601.498 .283\end{array}$ & 429.239 .800 & 1.540 .278 .169 \\
\hline
\end{tabular}


TABEL XV

MONEY LOST BERDASARKAN DOWNTIME (LANJUTAN)

\begin{tabular}{|c|c|c|}
\hline & Segment & TCM \\
\hline $\begin{array}{c}\text { Downtime Lost Time } \\
\text { (Hrs/3 Years) }\end{array}$ & 36,13884014 & 32,63839555 \\
\hline Lost Production Cost & $\mathrm{Rp} 1.264 .859 .405$ & $\mathrm{Rp} 1.142 .343 .844$ \\
\hline $\begin{array}{c}\text { Equipment/Sparepart } \\
\text { Cost }\end{array}$ & $\mathrm{Rp} 4.649 .861$ & $\mathrm{Rp} 3.669 .408$ \\
\hline $\begin{array}{c}\text { Labor Maintenance } \\
\text { Cost }\end{array}$ & $\mathrm{Rp} 2.635 .244$ & $\mathrm{Rp} 2.379 .991$ \\
\hline Downtime COUR & $\mathrm{Rp} 1.272 .144 .510$ & $\mathrm{Rp} 1.148 .393 .244$ \\
\hline
\end{tabular}

\section{KESIMPULAN}

Perhitungan RAM dengan menggunakan pemodelan RBD agar dapat melihat hubungan antar subsistem. Berdasarkan perhitungan reliability $24-936$ jam dengan interval 24 jam dan didapatkan hasil reliability system pada $\mathrm{t}=$ 936 jam sebesar 28,44\%. Waktu minimal subsistem mencapai kondisi awal dengan nilai maintainability sebesar 100\% adalah 13 jam. Nilai inherent availability sistem CCM 3 sebesar $99,47 \%$ dan nilai operational availability sistem CCM 3 sebesar 99,44\%. Berdasarkan target perusahaan dan key performance indicator IVARA, nilai availability tersebut sudah mencapai target. Biaya yang dihasilkan oleh masalah RAM sebesar Rp 5.031.295.257,00 berdasarkan pada downtime atau corrective time.

\section{DAFTAR PUSTAKA}

[1] Kemenperin, "Industri Baja Bangkit Tahun Ini," 2016. [Online].

Available: http://www.kemenperin.go.id/artikel/15400/IndustriBaja-Bangkit-Tahun-Ini.

[2] Kirana, U., Alhilman, J., \& Sutrisno, S. (2016). Perencanaan Kebijakan Perawatan Mesin Corazza FF100 Pada Line 3 PT XYZ Dengan Metode Reliability Centered Maintenance (RCM) II. Jurnal Rekayasa Sistem \& Industri (JRSI), 3(01), 47-53.

[3] F. Arina, P. Ferro, and A. Hamid, "Penentuan Keandalan Dengan Menggunakan Reliability Block Diagram ( RBD ) yang Berkonfigurasi Redundant Pada Mesin Boiler di PT . X,”. Seminar Nasional IENACO, pp. 1-7, 2013.

[4] B. Syam, S. Sinullingga, and I. Isranuri, "Analisis Reliability Dan Availability Mesin Pabrik Kelapa Sawit Pt . Perkebunan Nusantara 3," Dinamis, vol. II, no. 6, pp. 6-22, 2010.

[5] Dhamayanti, D., Alhilman, J., \& Athari, N. (2016). Usulan Preventive Maintenance Pada Mesin Komori LS440 Dengan Menggunakan Metode Reliability Centered Maintenance (RCM) II dan Risk Based Maintenance (RBM) di PT ABC. Jurnal Rekayasa Sistem \& Industri (JRSI), 3(02), 31-37.

[6] J. Moubray, Reliability Centered Maintenance. Industrial Press Inc, 1997.

[7] A. Weber and R. Thomas, "Key Performance Indicators - Measuring and Managing the Maintenance," IVARA Work Smart, 2005.
[8] C. Ebeling, An Introduction To Reliability and Maintainability Engineering. The McGraw-Hill Companies, 1997.

[9] F. Vicente, "Assesing the Cost of Unreliability in Gas Plant to Have a Sustainable Operation," IEEE, 2012.

[10] M. Bradley and R. Dawson, "The cost of unreliability: a case study," Quality, vol. 4, no. 3, pp. 212-218, 1998.

[11] H. P. Barringer, "Cost Of Unreliability," Barringer Assoc. Inc., 2008. 